\title{
Embedding the New Information Literacy Framework in Undergraduate Political Science Courses
}

Melissa Harden, University of Notre Dame
Jeffrey J. Harden, University of Notre Dame

ABSTRACT What information can I trust? What sources should I include in my paper? Where can I find a quote that fits my argument? Undergraduates ask instructors, classmates, and/or librarians these questions. Meanwhile, instructors bemoan the gap between their expectations for student writing and the finished products. Navigating a large volume of scholarship and critically evaluating potential sources is straightforward for faculty who have long passed key information literacy (IL) thresholds. However, students usually have not reached these thresholds themselves. We offer practical tools-grounded in a new framework for teaching IL_to address these challenges. We demonstrate how instructors can (and should) teach IL skills, with or without direct assistance from librarians. We recommend encouraging students to build context around information sources and slow down as they search. Implementing these tools moves students from passively synthesizing a limited set of (possibly biased) materials to engaging in genuine scholarly inquiry.

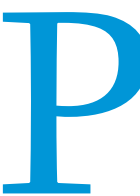
olitical science faculty often express discontent over undergraduate students' lack of preparedness for college-level research and writing. A common reason for these complaints is students' difficulty in demonstrating command of the material they use to support an argument. Perhaps they rely on sources that are known in the field as untrustworthy or select only those books and articles that favor their stated position. Similarly, students may cite only one viewpoint in a larger scholarly discussion about a topic. These problems, which reflect the need to develop students' information literacy (IL) skills, stand out starkly to faculty who have been writing for many years. However, the problems are not always obvious to students, who may not have passed key thresholds of expertise in working with information. This article discusses recent changes in the perspective of academic librarians on IL and presents simple solutions that can be implemented by instructors on their own and with minimal advanced preparation.

Information literacy-the ability to successfully and ethically engage with information and understand how it is produced and valued-is a crucial skill for undergraduates to develop.

Melissa Harden iD First Year Experience Librarian, Hesburgh Libraries, at the University of Notre Dame. She can be reached at mharden@nd.edu.

Jeffrey J. Harden ${ }^{D}$ is associate professor of political science at the University of Notre Dame. He can be reached at jeff.harden@nd.edu.
When students can critically evaluate sources, they better recognize the characteristics of the information ecosystem in which they engage on a daily basis. Yet, in a recent national survey, only about half of students and less than one fifth of faculty claimed that students are able to "confidently" evaluate information sources (Credo 2015). This problem may arise because faculty have spent years advancing their own information skills and thus are susceptible to assuming that students hold similar abilities. We contend that IL cannot be assumed at the beginning of the term and neither should it be left only to librarians to teach. Instructors must actively work to advance students' information skills-including allocating some class time-if they want to bring output from the course in line with their expectations.

Importantly, we discuss these issues in the context of a recent and major change in how academic librarians (especially in the United States) approach IL. In 2016, the Association of College and Research Libraries (ACRL), a division of the American Library Association, adopted the "Framework for Information Literacy for Higher Education" (hereafter "the Framework"). The Framework's content reflects a notable perspective shift from ACRL's previous document, the "Information Literacy Competency Standards for Higher Education" (hereafter "the Standards"; see ACRL 2015). ${ }^{1}$ Not surprisingly, then, the Framework reflects a significant shift in how many academic librarians approach IL instruction. 
This article addresses three objectives. First, we formally introduce the Framework to the literature on political science education. Second, we describe how IL skills can (and should) be taught by disciplinary faculty, with or without assistance from librarians on campus. Third, we provide illustrative examples of practical activities aligned to the Framework that instructors can implement skills of undergraduates in general-and political science majors specifically-are limited. As a result, typical students enrolled in political science courses often cannot search effectively for the information they need, evaluate the relative authority of various sources, and/or conceptualize scholarship as a conversation among different perspectives. In short, the current state of the disci-

\section{Instructors must actively work to advance students' information skills-including allocating some class time-if they want to bring output from the course in line with their expectations.}

quickly with minimal startup cost in the political science classroom. In discussing these points, we make the case that teaching IL facilitates deeper engagement with course content, ultimately improving the educational experience for both students and instructors.

\section{BACKGROUND}

The Framework defines IL as "[t]he set of integrated abilities encompassing the reflective discovery of information, the understanding of how information is produced and valued, and the use of information in creating new knowledge and participating ethically in communities of learning" (ACRL 2015). The Framework consists of the following six interconnected core concepts, or frames, that represent big ideas related to the use and production of information:

- authority is constructed and contextual

- information creation as a process

- information has value

- research as inquiry

- scholarship as conversation

- searching as strategic exploration

These frames encourage students to explore the complexity of encountering, using, and creating information. Each frame contains a set of knowledge practices and dispositions. They are written such that faculty can apply them to their teaching in disciplinary courses.

\section{POLITICAL SCIENCE AND INFORMATION LITERACY}

Disciplinary buy-in to teaching IL is critical because undergraduates across various academic fields generally lack advanced IL skills (Flierl et al. 2018). Moreover, teaching IL is perhaps even more important for political science faculty compared to those in other disciplines. Williams and Evans $(2008,117)$ made the case that "political science and information literacy seem inherently linked."2 Political science courses regularly provide forums for undergraduate students-including majors and nonmajors-to address important and complex issues facing society. Distilling these issues down to their most essential components is critical to fruitful dialogue in class discussion and students' written work.

However, current practice in political science typically does not match this significance. Williams and Evans $(2008,117)$ explained that the discipline "lags behind" other fields in consistently incorporating IL into instruction. They also demonstrated empirically that, prior to receiving any such instruction, the IL pline reflects a problematic tension. Although IL is universally important and particularly critical to political science, students taking courses in the discipline (both majors and nonmajors) often do not have the necessary skills. ${ }^{3}$

Fortunately, past research also demonstrates that dedicated IL instruction can be effective in improving students' work across various disciplines (Flierl et al. 2018) and specifically in political science courses (Gilbert, Knutson, and Gilbert 2012; Williams, Goodson, and Howard 2006; Williams and Evans 2008). For instance, Shannon and Shannon (2016) compared two iterations of the same course on international politicsadministered once with and once without an IL componentand found that IL instruction improved student papers on several dimensions, including the use of source material and overall quality (see also Marfleet and Dille 2005). However, to our knowledge, the Framework has not yet been formally introduced to political science. Instead, the current literature reflects the old Standards that were phased out in 2016 (Gilbert, Knutson, and Gilbert 2012; Stevens and Campbell 2008). The notable differences between the Framework and the Standards (Foasberg 2015) warrants an update that encompasses current best practices.

Additionally, the extant literature in political science places strong emphasis on direct librarian involvement in IL instruction. For instance, Gilbert, Knutson, and Gilbert (2012) described the benefits of adding a library laboratory component to a political science course, and Shannon and Shannon (2016) evaluated the effect of "embedding" a librarian in class during an entire semester. In general, these scholars take the position that even the "one-shot" library session, in which the class visits the library on a single day, is not enough (Shannon and Shannon 2016; Stevens and Campbell 2008). In our view, the embedded approach is useful under the right circumstances. However, it also presents challenges that might prevent faculty from adopting IL instruction at all.

Specifically, relying too heavily on direct librarian interaction requires substantial startup and continued investment of instructors' and librarians' time (Gilbert, Knutson, and Gilbert 2012, 117; Shannon and Shannon 2016, 466). This issue alone may be enough to dissuade faculty-who are also trying to publish, teach other courses, and complete service work-from adding IL into their curricula. Furthermore, embedding librarians in courses may not be possible at colleges and universities with small library faculties that already are stretched thin by their many responsibilities. Moreover, exclusively outsourcing IL instruction implicitly states that only librarians can teach those skills. 
Using the new Framework as a guide is an opportunity for political science instructors to incorporate IL into their course plans. These efforts could include library collaborations; however, our emphasis is on tools that do not require direct librarian involvement. Instead, we focus on instructional methods that faculty can quickly add to their syllabi before the course begins or even with little additional planning during the term. We contend that IL is important enough that it should be taught by political may still exist in the literature, which perspectives they agree or disagree with, and how they might proceed in pursuing a research question.

\section{SCHOLARSHIP AS CONVERSATION}

Thinking about scholarship as conversation can help students understand the importance of building the context of information sources that they find in the process of a research project

\section{Although IL is universally important and particularly critical to political science, students taking courses in the discipline (both majors and nonmajors) often do not have the necessary skills.}

science instructors alongside substantive content, with or without librarian involvement (Cassell 2018; Gooblar 2018). We anticipate that these low-cost approaches are more feasible for a wide range of instructors in political science.

\section{THE FRAMEWORK IN THE CLASSROOM}

Our strategies for teaching IL are rooted in the Framework and designed to address low or nonexistent IL skills in the political science classroom. Teaching IL need not involve an elaborate overhaul of courses or frequent collaboration with librarians. Instead, instructors can scaffold assignments and activities to allow students to engage with information relevant to course material as well as other areas of their lives. We briefly summarize several simple but effective activities (see the online supplementary materials for complete details). ${ }^{4}$

Although all six frames of the Framework can provide inspiration for instructors, the focus here is on two frames that are particularly relevant to undergraduate political science courses: (1) Scholarship as Conversation, and (2) Authority Is Constructed and Contextual. In doing so, we encourage faculty to focus on two crucial habits related to information creation and use: building (or rebuilding) context and slowing down.

First, the need to build context stems from the fact that a common first stop for student researchers-an online search engine-often produces results that are removed from their original contexts. Entries might include blog posts, scholarly articles, and social media links, all on the first page. Whereas determining which entries are valuable often is second nature to faculty, they appear the same to students. Likewise, the initial results pages in library catalogs and academic databases are snippets of information rather than complete entries. Journal articles appear outside the rest of the journal and may be mixed in with newspapers, books, or other resources. Understanding each resource and identifying the larger conversation(s) to which it belongs takes practice.

It also is important to build in opportunities for students to slow down when engaging with information. Indeed, they often have the endpoint in mind (i.e., their thesis statement or conclusion) before they get started, which incentivizes "cherry-picking" quotes from articles or refusing to acknowledge information that does not conform to their ideas. Slowing down and engaging with information in a meaningful way allows the research process to move them. In other words, students can identify the various perspectives on a given topic and think critically about where gaps or other assignment. Following is a description of this frame (ACRL 2015):

Communities of scholars, researchers, or professionals engage in sustained discourse with new insights and discoveries occurring over time as a result of varied perspectives and interpretations.

When students begin to understand this concept, they see information sources as part of a larger dialogue rather than as isolated artifacts. Faculty should demonstrate how researchers communicate through their scholarship, agreeing or disagreeing with one another and building from previous work. Students then will begin to learn the importance of seeking out multiple perspectives on a topic-and even recognize themselves as contributors to the conversation.

\section{Activity \#1: The Scholarly Dialogue}

One way to teach students to "listen in" on the scholarly conversation about a topic involves assigning as class readings published "back-and-forth" articles that address a specific research question. These scholarly dialogues are common in several political science journals. They are useful pedagogical tools because they provide examples of researchers directly engaging with one another. Students can follow the conversation by reading a few articles rather than an entire literature. In our suggested activity, students read one such conversation outside of class. Then, the instructor can devote some or all of class time for small-group and full-class discussions about how the researchers interact with one another, modeling how to analyze this conversation.

\section{Activity \#2: Follow the Conversation}

Another way to help students understand the idea of scholarship as conversation while teaching them to build context is to ask them to track down a resource cited in an assigned reading (i.e., follow the conversation back in time) and then search for the assigned reading in Google Scholar and find additional work that has cited the resource (i.e., following the conversation forward). Then, the instructor can ask students to analyze how these sources were used and/or cited by others. Importantly, this activity demonstrates to students that the scholarly record may omit certain voices or perspectives. In fact, peer-reviewed journal articles need not be the only type of sources that students use in this activity. Often, newspaper articles or long-form journalism also 
will work, demonstrating how the concept of conversation plays out in the nonscholarly sphere.

\section{AUTHORITY IS CONSTRUCTED AND CONTEXTUAL}

This frame is described as follows (ACRL 2015):

Information resources reflect their creators' expertise and credibility and are evaluated based on the information need and the context in which the information will be used. Authority is constructed in that various communities may recognize different types of authority. It is contextual in that the information need may help to determine the level of authority required.

Students should consider who is an authority regarding a topic of interest and why. This focus also can lead to discussions about how the ways in which we grant authority may be flawed.

\section{Activity \#3: Who Is an Authority?}

An easy in-class activity involves asking students to think about specific markers of authority in their own lives and in scholarship.
If activities like these are part of a lead-up to a research paper, they act as stepping stones in teaching students the type of analysis expected in their final document. They also give students practice in engaging with sources in a meaningful way rather than cherry-picking quotes to support initial thoughts, which allows for deeper engagement with course material. Finally, these activities inspire critical thinking in that students are asked to consider multiple perspectives and assess which ones are more or less credible.

\section{CONCLUSIONS}

Students often enter college with plenty of room to grow in their research and writing skills. However, faculty often place such a high premium on substantive material in their classes that they overlook the need to help students develop those skills during the course of a term. This tension stems from the fact that faculty who have made professional careers out of their ability to evaluate and communicate information have long passed key thresholds of information literacy. In contrast, a typical student likely has received little or no such training. Expecting students to produce

\section{If activities like these are part of a lead-up to a research paper, they act as stepping stones in teaching students the type of analysis expected in their final document.}

For instance, asking students about areas in which they are an expert themselves helps them to broadly recognize factors that confer expert status. Additionally, demonstrating that academic researchers may not be the only experts on a topic can be illuminating. Often, instructors notice that students use sources that are not widely considered to be authoritative. This activity builds requisite background knowledge for beginning to identify authorities in the field and leads to discussions about how authorities are identified in the discipline. Additionally, like Activity \#2, the discussion could emphasize ways in which the scholarly record may omit some perspectives; for instance, some individuals who are considered an authority in certain communities may not publish in the scholarly record. Furthermore, the instructor can emphasize in class that someone considered an authority in one context is not necessarily an authority in another context.

\section{Activity \#4: Assessing a Source}

An additional activity related to this frame that is particularly useful for helping students slow down involves working through a series of questions on a worksheet about a particular journal article, book chapter, or other source that they have read thoroughly. Answering these questions provides students not only the space to determine how a particular source informs their research but also helps them explore whether it is an authoritative source (and how it fits into the conversation on that topic). The questions can be modified to make the activity appropriate for a particular assignment or for upper-level students. The central idea is to provide a structured outlet for students to engage with sources and see the types of questions they should be asking as they read and research. Students could be assigned this worksheet after reading an article that they find on their own in the research process or one that is an assigned reading. research papers that draw correctly and comprehensively on scholarly and/or nonscholarly sources is unrealistic if instructors do not help them develop IL skills. Moreover, students need to practice these skills many times during the course of their undergraduate career concurrent with substantive material; one writing class in their first year is not enough experience.

Our discussion of the importance of teaching IL in political science classes merits an additional point about faculty relationships with libraries on campus. On the one hand, we encourage political science instructors to collaborate with librarians. They are trained to meet IL needs and can serve as a key resource in helping students pass the thresholds that faculty passed long ago. Indeed, librarians can assist at the assignment design stage as well as with instruction. On the other hand, we also contend that instructors are responsible for embedding IL into course material on their own. Doing so can help bring students' work in line with instructors' expectations for writing assignments. The activities described herein could be executed with or without direct instruction from a librarian and do not require a massive overhaul of course content.

We make the case for incorporating a new formal framework of IL skills into undergraduate political science courses. We discuss two frames from ACRL's Framework for Information Literacy for Higher Education and provide practical advice for implementing them in the classroom. We recommend that faculty include IL on the list of concepts that must be taught over the course of a term, similar to substantive topics. Instructors cannot assume that students learned how to engage with source material in high school or other college classes. Instead, as experts in information, they must assume some of the responsibility to educate students in this area. We anticipate that taking these steps will improve students' writing and allow faculty to focus more attention on students' substantive arguments when evaluating their work. 


\section{SUPPLEMENTARY MATERIAL}

To view supplementary material for this article, please visit https://doi.org/10.1017/S1049096519001756

\section{NOTES}

1. More specifically, the Framework represents a set of interconnected big ideas related to information discovery, use, and creation. It is descriptive, as opposed to the prescriptive Standards preceding it. Moreover, the Framework conveys information as contextual and socially constructed rather than as abjective, external commodity like the Standards (Foasberg 2015, 702).

2. Furthermore, the debate about "fake news" in modern politics directly underscores the Framework's value and further highlights the importance of teaching IL in political science courses. Applying lessons from IL around content found on the open web and social media can help students navigate the current information ecosystem (Caulfield 2017).

3. This problem is especially acute in lower-division courses with larger proportions of first- and second-year students. However, even students well into their college careers suffer from low IL (Williams and Evans 2008).

4. Instructors also may want to evaluate the effectiveness of these activities in their courses. A simple and informal comparison of student work in terms with and without the exercises may be sufficient. Alternatively, with some initial preparation, the instructor could implement a more forma quantitative design to evaluate the impact of the exercises on students IL skills. For examples of these designs in political science, see Gilbert, Knutson, and Gilbert (2012), Shannon and Shannon (2016), and Williams and Evans (2008).

\section{REFEREN C ES}

Association of College and Research Libraries (ACRL). 2015. "Framework for Information Literacy for Higher Education.” Available at www.ala.org/acrl/ standards/ilframework. Accessed May 6, 2019
Cassell, Mark K. 2018. "When the World Helps Teach Your Class: Using Wikipedia to Teach Controversial Issues." PS: Political Science \& Politics 51 (2): 427-33.

Caulfield, Mike A. 2017. Web Literacy for Student Fact-Checkers. Available at https:// webliteracy.pressbooks.com. Accessed May 6, 2019.

Credo. 2015. "Credo Survey: Faculty Teach Information Literacy in Response to Lack of Student Skills." Available at https://corp.credoreference.com/why-credo/ newsroom/457-2015-survey-pr.html. Accessed April 29, 2019.

Flierl, Michael, Emily Bonem, Clarence Maybee, and Rachel Fundator. 2018. "Information Literacy Supporting Student Motivation and Performance: Course-Level Analyses." Library \& Information Research 40 (1): 30-37.

Foasberg, Nancy M. 2015. "From Standards to Frameworks for IL: How the ACRL Framework Addresses Critiques of the Standards." Portal: Libraries and the Academy 15 (4): 699-717.

Gilbert, Julie K., Katherine Knutson, and Christopher P. Gilbert. 2012. “Adding an Integrated Library Component to an Undergraduate Research Methods Course." PS: Political Science \& Politics 45 (1): 112-18.

Gooblar, David. 2018. "How to Teach Information Literacy in an Era of Lies." The Chronicle of Higher Education, July 24. Available at www.chronicle.com/article/ How-to-Teach-Information/243973. Accessed May 6, 2019.

Marfleet, B. Gregory, and Brian J. Dille. 2005. "Information Literacy and the Undergraduate Research Methods Curriculum." Journal of Political Science Education 1 (2): 175-90.

Shannon, Amanda, and Vaughn Shannon. 2016. "Librarians in the Midst: Improving Student Research Through Collaborative Instruction." Journal of Political Science Education 12 (4): 457-70.

Stevens, Christy R., and Patricia J. Campbell. 2008. "Collaborating with Librarians to Develop Lower Division Political Science Students' Information Literacy Competencies." Journal of Political Science Education 4 (2): 225-52.

Williams, Michelle Hale, and Jocelyn Jones Evans. 2008. "Factors in Information Literacy Education." Journal of Political Science Education 4 (1): 116-30.

Williams, Michelle Hale, Kymberly Anne Goodson, and W. Gary Howard. 2006 "Weighing the Research Paper Option: The Difference that Information Literacy Skills Can Make." PS: Political Science \& Politics 39 (3): 513-19. 